\title{
Structured substrates and delivery vehicles: trending now in biomedicine
}

\author{
"Biomedicine has entered the era of biofunctional \\ biomaterials."
}

First draft submitted: 5 May 2016; Accepted for publication: 13 May 2016; Published online: 7 June 2016

Biomedicine has entered the era of biofunctional biomaterials [1-6]. These are materials that utilize biophysical (e.g., topography [712]), biochemical (e.g., drug delivery [13-18]) and biological (e.g., gene delivery [19-24]) signals to control cellular functions in both in vitro and in vivo setting. In vitro, biofunctional materials aspire to either maintain the phenotype fidelity of permanently differentiated cells or direct stem cells toward specific lineage. In vivo, biofunctional materials desire to positively interact with host cells and surrounding tissues and promote functional repair and regeneration. The former frequently utilizes a structured substrate (e.g., electro-spun scaffolds, imprinted substrates) that would imitate the topographical/ architectural features of the tissue from which the cells were derived from (in the case of permanently differentiated cells) or the tissue that the cells are due to be implanted in (in the case of stem cells). The latter often uses a delivery vehicle (e.g., hydrogels, particles, dendrimers, micelles) that would support sustained and localized delivery of its cargo (e.g., cells, drugs, genes, growth factors).

Electro-spun scaffolds and imprinted substrates have become an inherent element of modern biomedicine [25-30]. Indicative recent highlights of the electro-spinning technology include: formation of three-dimensional structures of controlled porosity [31], production of substrates for the differentiation of stem cells toward specific lineage [32], fabrication of delivery vehicles of biofunctional molecules for hypertrophic scars [33], development of high sensitivity acoustic sensors [34], assembly of high-performance lithium ion batteries [35]. Although nanoto microscale imprinted substrates did not bring about the anticipated effect in in vivo setting [36,37], numerous advances have been achieved recently, including: development of substrates with optimal dimensionality for osteogenic differentiation of human bone marrow stem cells [38], fabrication of electrode arrays to monitor the dopaminergic differentiation of human neural stem cells [39], production of electro-conductive nano-patterned substrates with enhanced myogenic differentiation and maturation capacity [40], construction of microfluidic devices [41], even manufacturing of high-performance lithium-ion micro-batteries [42]. The multimodal capacity/potential of structured technologies is undeniable. Refinement of engineering and manufacturing technologies in the years to come would enable more accurate and reproducible production of structured substrates at high volume and low cost, revolutionizing that way multiple disciplines, including biomedicine, filtration, imaging, energy and computing.

Modern biomedicine requires localized and sustained delivery of bioactive molecules, therapeutic agents, trophic factors and viable cell populations to activate/enhance the innate reparative host capacity. The rationale of using delivery vehicles is based on the fact that direct cell injections suffer from celllocalization at the injury site [43], systemic drug delivery is associated with toxicity of the

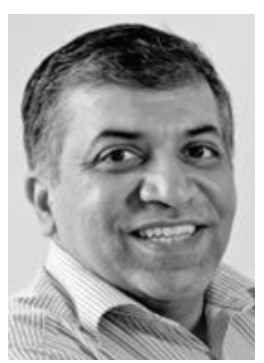

Abhay Pandit

Science Foundation Ireland (SFI) Centre for Research in Medical Devices (CÚRAM), Biomedical Sciences Building, National University of Ireland Galway (NUI Galway), Galway, Ireland

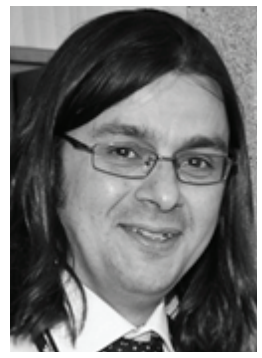

Dimitrios I Zeugolis

Author for correspondence:

Science Foundation Ireland (SFI)

Centre for Research in Medical Devices (CÚRAM), Biomedical Sciences Building, National University of Ireland Galway (NUI Galway), Galway, Ireland and

Regenerative, Modular \& Developmental Engineering Laboratory (REMODEL),

Biomedical Sciences Building, National University of Ireland Galway (NUI Galway), Galway, Ireland

Tel.: +353091493166

Fax: +353091563991

dimitrios.zeugolis@nuigalway.ie

Future $\because$ Medicine part of 
nontargeted tissues/organs at the effective concentration [44-46], growth factors have half-life in the region of 30-150 min [47,48], imposing the need for multiple and high dose injections for an effective outcome [49-51]. To this end, numerous delivery vehicles (e.g., hydrogels, particles, dendrimers, micelles) are under intense investigation.

Natural and synthetic in origin nano-gels, microgels and hydrogels are emerging delivery platforms in tissue engineering due to their excellent biocompatibility; tunable architectural features, mechanical properties and degradation rate; capacity to deliver any cargo; and diverse clinical target application [52-55]. To date such systems have been utilized for numerous biomedical applications, including: peptide and protein delivery vehicles [56], cell delivery platforms with the capacity to modulate angiogenic paracrine responses [57], three-dimensional platforms (e.g., microfluidic or array) to study cell responses in vitro [58-60].

\section{"Biofunctional biomaterials are on the way to revolutionize healthcare.}

Nano- and microparticles also constitute a significant asset in our regenerative/reparative toolbox. Such systems have been used extensively for controlled delivery of drugs [61], vaccines [62] and genes [63]. Advances in their fabrication process allow control over their size, shape, surface charge and rigidity, which subsequently control cellular phagocytosis and endocytosis; circulation time; biodistribution and targeting [64,65]. Nanoparticles have also found applications as stem cell tracking devices [66], as cancer theranostics [67] and as imaging agents [68].

Dendrimers are highly branched, star-shaped and nano-meter in dimension macromolecules that are comprised of a central core, an interior dendritic structure and an exterior surface with multiple functional surface groups. Theoretical and computational studies are employed to elucidate their physical and chemical properties and to explore their interactions with the intended cargo and target tissue [69]. Their multibranched dendritic structure, multivalency, enhanced permeability and retention and optional stimuliresponsiveness properties make them interesting agents for targeted delivery of various cargos [70,71]. Triazine dendrimers, for example, benefit from their synthetic versatility and well-defined structure and have been used extensively in drug delivery, nonviral DNA and RNA delivery and for sensing applications [72]. The use of self-immolative dendrimers has been advocated as their backbone structure allows cascade decomposition and fragmentation into either biodegradable or easily excreted from the body molecules [73]. High generation poly-(amidoamine) (PAMAM) and poly(propylenimine) (PPI) dendrimers, the most widely used dendrimers, exhibit higher grafting percentages and high transfection activity [74]. Unfortunately, issues associated with toxicity (e.g., high generation unmodified cationic dendrimers) [75,76] have triggered investigations into alternative delivery vehicles.

Polymeric micelles are nano-scale supramolecular core-shell assemblies of amphiphilic block copolymers. The hydrophobic core allows encapsulation of hydrophobic cargos, while the hydrophilic shell enables prolonged circulation in the blood. Theoretical principles have been used to set design parameters (e.g., composition, size, structure) and assess functionality (e.g., cargo loading and release, stability, intracellular delivery, biodistribution) [77]. Numerous building blocks have been assessed to-date as delivery vehicles of peptides, drugs and genes. For example, phospholipid micelles have been advocated for the delivery of peptides, as they do not compromise their bioactivity, protect them against proteolytic degradation and enhance their efficacy [78]. Poly(amino acid) and its derivatives are favored for drug delivery due to their biodegradability, biocompatibility and availability of side functional groups [79]. Current trends focus into the incorporation of stimuli-responsive moieties for the spatiotemporal release of the cargo [80]. For example, redox $[81,82]$ and $\mathrm{pH}[83,84]$ sensitive moieties allow the payload drug/gene to be released almost exclusively, for example, at the cancer/inflammation site.

In this special issue, we discuss recent advancements in nanomedicine and their impact in healthcare $[85,86]$. Among others, herein, we discuss recent strides in the field of design [87], synthesis [88,89] and fabrication [90,91] of structured materials [92,93], stimuli-responsive materials [94] and delivery systems [95-98] for regenerative medicine purposes. It is evidenced that we are on our way to revolutionize healthcare.

\section{Financial \& competing interests disclosure}

This publication has been supported by the Health Research Board (grant agreement number: HRA_POR/2011/84) and the Science Foundation Ireland and the European Regional Development Fund (grant agreement number: 13/RC/2073). The authors have no other relevant affiliations or financial involvement with any organization or entity with a financial interest in or financial conflict with the subject matter or materials discussed in the manuscript apart from those disclosed.

No writing assistance was utilized in the production of this manuscript. 


\section{References}

1 Kumar S, Raj S, Sarkar K, Chatterjee K. Engineering a multi-biofunctional composite using poly(ethylenimine) decorated graphene oxide for bone tissue regeneration. Nanoscale 8(12), 6820-6836 (2016).

2 Bhatia D, Sharma S, Krishnan Y. Synthetic, biofunctional nucleic acid-based molecular devices. Curr. Opin. Biotechnol. 22(4), 475-484 (2011).

3 Quadir M, Haag R. Biofunctional nanosystems based on dendritic polymers. J. Control. Release 161(2), 484-495 (2012).

4 Saik J, Mchale M, West J. Biofunctional materials for directing vascular development. Curr. Vasc. Pharmacol. 10(3), 331-341 (2012).

5 Salimath A, García A. Biofunctional hydrogels for skeletal muscle constructs. J. Tissue Eng. Regen. Med. doi:10.1002/ term.1881 (2014) (Epub ahead of print).

6 Zeugolis D, Pandit A. Biofunctional biomaterials: the next frontier. Bioconjug. Chem. 26(7), 1157 (2015).

$7 \quad$ Yang Y, Leong K. Nanoscale surfacing for regenerative medicine. Wiley Interdiscip. Rev. Nanomed. Nanobiotechnol. 2(5), 478-495 (2010).

8 Chen W, Shao Y, Li X, Zhao G, Fu J. Nanotopographical surfaces for stem cell fate control: engineering mechanobiology from the bottom. Nano Today 9(6), 759-784 (2014).

9 Tay C, Irvine S, Boey F, Tan L, Venkatraman S. Micro-/ nano-engineered cellular responses for soft tissue engineering and biomedical applications. Small 7(10), 1361-1378 (2011).

10 An J, Chua C, Yu T, Li H, Tan L. Advanced nanobiomaterial strategies for the development of organized tissue engineering constructs. Nanomedicine (Lond.) 8(4), 591-602 (2013).

11 Salmasi S, Kalaskar D, Yoon W, Blunn G, Seifalian A. Role of nanotopography in the development of tissue engineered $3 \mathrm{D}$ organs and tissues using mesenchymal stem cells. World J. Stem Cells 7(2), 266-280 (2015).

12 Zhang Y, Gordon A, Qian W, Chen W. Engineering nanoscale stem cell niche: direct stem cell behavior at cellmatrix interface. Adv. Healthc. Mater. 4(13), 1900-1914 (2015).

13 Oltra N, Swift J, Mahmud A, Rajagopal K, Loverdea S, Discher D. Filomicelles in nanomedicine: from flexible, fragmentable, and ligand-targetable drug carrier designs to combination therapy for brain tumors. J. Mater. Chem. B 1, 5177-5185 (2013).

14 Yucel T, Lovett M, Kaplan D. Silk-based biomaterials for sustained drug delivery. J. Control. Release 190, 381-397 (2014).

15 Stebbins N, Ouimet M, Uhrich K. Antibiotic-containing polymers for localized, sustained drug delivery. Adv. Drug Deliv. Rev. 78, 77-87 (2014).

16 Trivedi R, Kompella U. Nanomicellar formulations for sustained drug delivery: strategies and underlying principles. Nanomedicine (Lond.) 5(3), 485-505 (2010).

17 Karami Z, Hamidi M. Cubosomes: remarkable drug delivery potential. Drug Discov. Today doi:10.1016/j. drudis.2016.01.004 (2016) (Epub ahead of print).
18 Ferguson S, Nguyen J. Exosomes as therapeutics: the implications of molecular composition and exosomal heterogeneity. J. Control. Release 228, 179-190 (2016)

19 Loh X, Lee T, Dou Q, Deen G. Utilising inorganic nanocarriers for gene delivery. Biomater. Sci. 4(1), 70-86 (2015).

20 Raad M, Teunissen E, Mastrobattista E. Peptide vectors for gene delivery: from single peptides to multifunctional peptide nanocarriers. Nanomedicine (Lond.) 9(14), 2217-2232 (2014)

21 Hill A, Chen M, Chen C, Pfeifer B, Jones C. Overcoming gene-delivery hurdles: physiological considerations for nonviral vectors. Trends Biotechnol. 34(2), 91-105 (2016).

22 Yang J, Zhang Q, Chang H, Cheng Y. Surface-engineered dendrimers in gene delivery. Chem. Rev. 115(11), 5274-5300 (2015).

23 Gower R, Shea L. Biomaterial scaffolds for controlled, localized gene delivery of regenerative factors. Adv. Wound Care (New Rochelle) 2(3), 100-1006 (2013).

24 Oliveira C, Silveira I, Veiga F, Ribeiro A. Recent advances in characterization of nonviral vectors for delivery of nucleic acids: impact on their biological performance. Expert Opin. Drug Deliv. 12(1), 27-39 (2015).

25 Biggs M, Pandit A, Zeugolis D. Two-dimensional imprinted substrates and three-dimensional electro-spun scaffolds revolutionise biomedicine. Nanomedicine (Lond.) (2016) (In Press).

26 Lu Y, Huang J, Yu G et al. Coaxial electrospun fibers: applications in drug delivery and tissue engineering. Wiley Interdiscip. Rev. Nanomed. Nanobiotechnol. (2016) (In Press).

27 Chou S, Carson D, Woodrow K. Current strategies for sustaining drug release from electrospun nanofibers. J. Control. Release 220(B), 584-591 (2015).

28 Fuller K, Pandit A, Zeugolis D. The multifaceted potential of electro-spinning in regenerative medicine. Pharm. Nanotechnol. 2(1), 23-34 (2014).

29 Resende R, Fonseca E, Tonelli F et al. Scale/topography of substrates surface resembling extracellular matrix for tissue engineering. J. Biomed. Nanotechnol. 10(7), 1157-1193 (2014).

30 Miyoshi $\mathrm{H}$, Adachi T. Topography design concept of a tissue engineering scaffold for controlling cell function and fate through actin cytoskeletal modulation. Tissue Eng. B Rev. 20(6), 609-627 (2014)

31 Fuller K, Gaspar D, Delgado L, Pandit A, Zeugolis D. The influence of porosity and pore shape on structural, mechanical and biological properties of poly e-caprolactone electro-spun fibrous scaffolds. Nanomedicine (Lond.) (2016) (In Press)

32 Mohtaram N, Ko J, King C et al. Electrospun biomaterial scaffolds with varied topographies for neuronal differentiation of human-induced pluripotent stem cells. J. Biomed. Mater. Res. A 103(8), 2591-2601 (2015).

33 Cheng L, Sun X, Zhao X et al. Surface biofunctional drugloaded electrospun fibrous scaffolds for comprehensive repairing hypertrophic scars. Biomaterials 83, 169-181 (2016). 
34 Lang C, Fang J, Shao H, Ding X, Lin T. High-sensitivity acoustic sensors from nanofibre webs. Nat. Commun. 7 , 11108 (2016).

35 Wang H, Lu X, Li L et al. Synthesis of SnO2versus Sn crystals within $\mathrm{N}$-doped porous carbon nanofibers via electrospinning toward high-performance lithium ion batteries. Nanoscale 8(14), 7595-7603 (2016).

36 English A, Azeem A, Spanoudes K et al. Substrate topography: a valuable in vitro tool, but a clinical red herring for in vivo tenogenesis. Acta Biomater. 27, 3-12 (2015).

37 Azeem A, English A, Kumar P et al. The influence of anisotropic nano- to micro-topography on in vitro and in vivo osteogenesis. Nanomedicine (Lond.) 10(5), 693-711 (2015).

38 Carvalho A, Pelaez-Vargas A, Hansford D, Fernandes M, Monteiro F. Effects of line and pillar array microengineered $\mathrm{SiO} 2$ thin films on the osteogenic differentiation of human bone marrow-derived mesenchymal stem cells. Langmuir 32(4), 1091-1100 (2016).

39 Kim T, Yea C, Chueng S et al. Large-scale nanoelectrode arrays to monitor the dopaminergic differentiation of human neural stem cells. Adv. Mater. 27(41), 6356-6362 (2015).

40 Yang H, Lee B, Tsui J et al. Electroconductive nanopatterned substrates for enhanced myogenic differentiation and maturation. Adv. Healthc. Mater. 5(1), 137-145 (2016).

41 Chen J, Zhou Y, Wang D et al. UV-nanoimprint lithography as a tool to develop flexible microfluidic devices for electrochemical detection. Lab Chip 15(14), 3086-3094 (2015).

42 Ning H, Pikul J, Zhang R et al. Holographic patterning of high-performance on-chip 3D lithium-ion microbatteries. Proc. Natl Acad. Sci. USA 112(21), 6573-6578 (2015).

43 Abbah S, Spanoudes K, O’Brien T, Pandit A, Zeugolis D. Assessment of stem cell carriers for tendon tissue engineering in pre-clinical models. Stem Cell. Res. Ther. 5(2), 38 (2014).

44 Xinluan W, Yuxiao L, Helena N, Zhijun Y, Ling Q. Systemic drug delivery systems for bone tissue regeneration: a mini review. Curr. Pharm. Des. 21(12), 1575-1583 (2015).

45 Harris E, Tiganescu A, Tubeuf S, Mackie S. The prediction and monitoring of toxicity associated with long-term systemic glucocorticoid therapy. Curr. Rheumatol. Rep. 17(6), 513 (2015).

46 Curigliano G, Mayer E, Burstein H, Winer E, Goldhirsch A. Cardiac toxicity from systemic cancer therapy: a comprehensive review. Prog. Cardiovasc. Dis. 53(2), 94-104 (2010).

47 Khosravi A, Cutler C, Kelly M et al. Determination of the elimination half-life of fibroblast growth factor-23. J. Clin. Endocrinol. Metab. 92(6), 2374-2377 (2007).

48 Gay C, Winkles J. The half-lives of platelet-derived growth factor A- and B-chain mRNAs are similar in endothelial cells and unaffected by heparin-binding growth factor-1 or cycloheximide. J. Cell. Physiol. 147(1), 121-127 (1991).

49 Eppler S, Combs D, Henry T et al. A target-mediated model to describe the pharmacokinetics and hemodynamic effects of recombinant human vascular endothelial growth factor in humans. Clin. Pharmacol. Ther. 72(1), 20-32 (2002).

50 Simons M, Annex B, Laham R et al. Pharmacological treatment of coronary artery disease with recombinant fibroblast growth factor-2: double-blind, randomized, controlled clinical trial. Circulation 105(7), 788-793 (2002).

51 Henry T, Annex B, Mckendall G et al. The VIVA trial: Vascular endothelial growth factor in ischemia for vascular angiogenesis. Circulation 107(10), 1359-1365 (2003).

52 Jiang Y, Chen J, Deng C, Suuronen E, Zhong Z. Click hydrogels, microgels and nanogels: emerging platforms for drug delivery and tissue engineering. Biomaterials 35(18), 4969-4985 (2014).

53 Zhang H, Zhai Y, Wang J, Zhai G. New progress and prospects: the application of nanogel in drug delivery. Mater. Sci. Eng. C Mater. Biol. Appl. 60, 560-568 (2016).

54 Molina M, Asadian-Birjand M, Balach J, Bergueiro J, Miceli E, Calderón M. Stimuli-responsive nanogel composites and their application in nanomedicine. Chem. Soc. Rev. 44(17), 6161-6186 (2015).

55 Wang H, Heilshorn S. Adaptable hydrogel networks with reversible linkages for tissue engineering. Adv. Mater. 27(25), 3717-3736 (2015).

56 Bysell H, Månsson R, Hansson P, Malmsten M. Microgels and microcapsules in peptide and protein drug delivery. $A d v$. Drug Deliv. Rev. 63(13), 1172-1185 (2011).

57 Thomas D, Fontana G, Chen X et al. A shape-controlled tuneable microgel platform to modulate angiogenic paracrine responses in stem cells. Biomaterials 35(31), 8757-8766 (2014).

58 Siltanen C, Yaghoobi M, Haque A et al. Microfluidic fabrication of bioactive microgels for rapid formation and enhanced differentiation of stem cell spheroids. Acta Biomater. 34, 125-132 (2016).

59 Li Y, Chen P, Wang Y et al. Rapid assembly of heterogeneous $3 \mathrm{D}$ cell microenvironments in a microgel array. Adv. Mater. 28(18), 3543-3548 (2016).

60 Vu L, Jain G, Veres B, Rajagopalan P. Cell migration on planar and three-dimensional matrices: a hydrogel-based perspective. Tissue Eng. B Rev. 21(1), 67-74 (2015).

61 Lim H, Tey B, Chan E. Particle designs for the stabilization and controlled-delivery of protein drugs by biopolymers: a case study on insulin. J. Control. Release 186 11-21 (2014).

62 Yue H, Ma G. Polymeric micro/nanoparticles: Particle design and potential vaccine delivery applications. Vaccine 33(44), 5927-5936 (2015).

63 Mitra R, Zheng M, Han Z. Nanoparticle-motivated gene delivery for ophthalmic application. Wiley Interdiscip. Rev. Nanomed. Nanobiotechnol. 8(1), 160-174 (2016).

64 Anselmo A, Zhang M, Kumar S et al. Elasticity of nanoparticles influences their blood circulation, phagocytosis, endocytosis, and targeting. ACS Nano 9(3), 3169-3177 (2015).

65 Anselmo A, Mitragotri S. Impact of particle elasticity on particle-based drug delivery systems. Adv. Drug Deliv. Rev. doi:10.1016/j.addr.2016.01.007 (2016) (Epub ahead of print).

66 Accomasso L, Gallina C, Turinetto V, Giachino C. Stem cell tracking with nanoparticles for regenerative medicine purposes: an overview. Stem Cells Int. 2016, 7920358 (2016). 
, Yang V, David A. Cancer theranostics: the rise of targeted magnetic nanoparticles. Trends Biotechnol. 29(7), 323-332 (2011).

Pratt E, Shaffer T, Grimm J. Nanoparticles and radiotracers: advances toward radionanomedicine. Wiley Interdiscip. Rev. Nanomed. Nanobiotechnol. doi:10.1002/wnan.1402 (2016) (Epub ahead of print)

69 Tian W, Ma Y. Theoretical and computational studies of dendrimers as delivery vectors. Chem. Soc. Rev. 42(2), 705-727 (2013).

70 Somani S, Dufès C. Applications of dendrimers for brain delivery and cancer therapy. Nanomedicine (Lond.) 9(15), 2403-2414 (2014).

71 Wang H, Huang Q, Chang H, Xiao J, Cheng Y. Stimuliresponsive dendrimers in drug delivery. Biomater. Sci. 4(3), 375-390 (2016).

72 Lim J, Simanek E. Triazine dendrimers as drug delivery systems: from synthesis to therapy. Adv. Drug Deliv. Rev. 64(9), 826-835 (2012).

73 Wang R, Costanza F, Niu Y et al. Development of selfimmolative dendrimers for drug delivery and sensing. J. Control. Release 159(2), 154-163 (2012).

74 Hashemi M, Tabatabai S, Parhiz H et al. Gene delivery efficiency and cytotoxicity of heterocyclic amine-modified PAMAM and PPI dendrimers. Mater. Sci. Eng. C Mater. Biol. Appl. 61, 791-800 (2016).

75 Sadekar S, Ghandehari H. Transepithelial transport and toxicity of PAMAM dendrimers: implications for oral drug delivery. Adv. Drug Deliv. Rev. 64(6), 571-588 (2012).

76 Shcharbin D, Janaszewska A, Klajnert-Maculewicz B et al. How to study dendrimers and dendriplexes III. Biodistribution, pharmacokinetics and toxicity in vivo. J. Control. Release 181, 40-52 (2014).

77 Li W, Feng S, Guo Y. Tailoring polymeric micelles to optimize delivery to solid tumors. Nanomedicine (Lond.) 7(8), 1235-1252 (2012).

78 Banerjee A, Onyuksel H. Peptide delivery using phospholipid micelles. Wiley Interdiscip. Rev. Nanomed. Nanobiotechnol. 4(5), 562-574 (2012).

$79 \mathrm{Xu} \mathrm{H}$, Yao Q, Cai C et al. Amphiphilic poly(amino acid) based micelles applied to drug delivery: the in vitro and in vivo challenges and the corresponding potential strategies. J. Control. Release 199, 84-97 (2015).

80 Li Y, Xiao K, Zhu W, Deng W, Lam K. Stimuli-responsive cross-linked micelles for on-demand drug delivery against cancers. Adv. Drug Deliv. Rev. 66, 58-73 (2014).

81 Zhang P, Zhang H, He W, Zhao D, Song A, Luan Y. Disulfide-linked amphiphilic polymer-docetaxel conjugates assembled redox-sensitive micelles for efficient anti-tumor drug delivery. Biomacromolecules 17(5), 1621-1632 (2016).

82 Zhang H, Wang K, Zhang P, He W, Song A, Luan Y. Redoxsensitive micelles assembled from amphiphilic mPEG-PCLSS-DTX conjugates for the delivery of docetaxel. Colloids Surf. B Biointerfaces 142, 89-97 (2016).
83 Liu Z, Zhang N. pH-sensitive polymeric micelles for programmable drug and gene delivery. Curr. Pharm. Des. 18(23), 3442-3451 (2012).

84 Rongbin H, Lei X, Ying L et al. Synthesis and in vitro evaluation of $\mathrm{pH}$-sensitive PEG-I-dC16 block polymer micelles for anticancer drug delivery. J. Pharm. Pharmacol. doi:10.1111/jphp.12545 (2016) (Epub ahead of print).

85 Venugopal J, Ramakrishna S. Nanotechnology: 21st century revolution in restorative healthcare. Nanomedicine (Lond.) 11(12), 1511-1513 (2016).

86 Khademhosseini A, Jang H, Zhang Y. Boosting clinical translation of nanomedicine. Nanomedicine (Lond.) 11(12), 1489-1493 (2016).

87 Guarino V, Ambrosio L. Electrofluidodynamics: exploring new toolbox to design biomaterials for tissue regeneration and degeneration. Nanomedicine (Lond.) 11(12), 1515-1518 (2016).

88 Discher D, Nair P, Karthick S, Spinler K, Vakili M, Lavasanifar A. Filomicelles from aromatic diblock copolymers increase tumor cell death and aneuploidy compared with aliphatic copolymers. Nanomedicine (Lond.) 11(12), 1551-1569 (2016).

89 Weiss A, Hiob M, Trane A, Wise S, Bernatchez P. Tropoelastin enhances nitric oxide production by endothelial cells. Nanomedicine (Lond.) 11(12), 1489-1493 (2016).

90 James R, Laurencin C. Nanofiber technology: it's transformative role in nanomedicine. Nanomedicine (Lond.) 11(12), 1499-1501 (2016).

91 Bentley W, Terrell J, Payne G. Networking biofabricated systems through molecular communication. Nanomedicine (Lond.) 11(12), 1503-1506 (2016).

92 Ma P, Zhang Z, Eyster T. Nano-structured injectable cell micro-carriers for tissue regeneration. Nanomedicine (Lond.) 11(12), 1611-1628 (2016).

93 Pek Y, Wu H, Chow E, Ying J. Transparent nanostructured photochromic UV-blocking soft contact lenses. Nanomedicine (Lond.) 11(12), 1599-1610 (2016).

94 Alsberg E, Huynh C, Nguyen M, Naris M, Tonga G, Rotello V. Light triggered siRNA release and induction of hMSC osteogenesis via photodegradable, dual-crosslinked hydrogels. Nanomedicine (Lond.) 11(12), 1535-1550 (2016).

95 Rotello V, Jeong Y, Kim S et al. Nanoparticle-dendrimer hybrid nanocapsules for therapeutic delivery. Nanomedicine (Lond.) 11(12), 1571-1578 (2016).

96 Highley C, Kim M, Lee D, Burdick J. Near-infrared littletriggered dissociation of supramolecular host-guest microgels for therapeutic delivery. Nanomedicine (Lond.) 11(12), 1579-1590 (2016).

97 Banfi A, Di Maggio N, Martella E et al. Rapid and efficient magnetization of mesenchymal stem cells by dendrimerfunctionalized magnetic nanoparticles. Nanomedicine (Lond.) 11(12), 1519-1534 (2016).

98 Wischke C, Lendlein A. Functional nanocarriers by miniaturization of polymeric materials. Nanomedicine (Lond.) 11(12), 1507-1509 (2016). 